Original Article

\title{
Efficacy of Evidence Based Practice (EBP) Guideline to Prevent and Treat Breast Engorgement among Post Caesarean Mothers in Selected Hospital in Mangalore.
}

\author{
Timi Thomas ${ }^{1}$, Elsa Sanatombi Devi ${ }^{2}$, Linu Sara George ${ }^{3}$ \\ ${ }^{1}$ Assistant Professor, Department of Obstetrics and Gynecological Nursing , Nitte Usha Institute of Nursing Sciences, \\ ${ }^{2}$ Professor \& HOD Medical \& Surgical Nursing, ${ }^{3}$ Professor \& HOD, Principles and Practices of Nursing, Manipal college of \\ Nursing, Manipal
}

* Corresponding Author : Timi Thomas, Assistant Professor, Department of Obstetrics and Gynecological Nursing, Nitte Usha Institute of Nursing Sciences, Deralakatte. Mobile : +918123765753 E-mail : timjith@gmail.com.

Received

: 15.05 .2016

Review Completed : 12.12.2016

Accepted

:02.01.2017

Keywords : EBP Guideline, Breast engorgement, Post caesarean mothers

\begin{tabular}{|c|}
\hline Access this article online \\
\hline Quick Response Code \\
\hline
\end{tabular}

\section{Abstract}

Introduction: Early initiation of breast feeding has long been recognized as one of the most important contributor to mothers' as well as infants' health. Breast feeding should be initiated within half an hour and two hour of birth in normal vaginal delivery and caesarean section respectively. A recent systematic review regarding the timing of breast feeding initiation shows that if newborns are exposed to breast feeding at the early stage, they are much more likely to adhere to breast feeding and ultimately have better outcome in terms of less incidence of breast engorgement.

Objectives: The objectives of the study were to identify the early initiation of breast feeding by post caesarean mothers using observational check list, to train the staff nurses regarding the EBP guideline to prevent and treat breast engorgement among post caesarean mothers, to find the difference between pre test knowledge score and post test knowledge score among staff nurses on prevention and treatment of breast engorgement using structured knowledge questionnaire, to assess the effectiveness of EBP guideline to prevent and treat breast engorgement among post caesarean mothers in terms of reduction in the severity of breast engorgement before and after the implementation of EBP guideline using modified six point engorgement scale.

Methods: In this study, one group pre test post test design was chosen. The study was conducted at KM C Hospital Attawar, Mangalore. The population in this study comprised of prime post cesarean mothers and staff nurses who are available at the period of data collection at KM CHospital, Attawar, M angalore. The calculated sample size for post caesarean mothers is 50 ad staff nurses are 20. The following tools were used to collect the data from the study samples. 1) Baseline characteristics - post caesarean mothers and staff nurses 2) Structured knowledge questionnaire on prevention and treatment of breast engorgement 3) Observational checklist to identify early initiation of breast feeding 4) M odified six point engorgement scale to assess the severity of breast engorgement. The data were collected and analyzed by using descriptive and inferential statistics by SPSS package version 16 .

Results: The study results shows, Out of the 50 mothers, 26 (52\%) of the mothers had previous information regarding breast engorgement. 14 (53\%) of the mothers had received information from family members/ relatives and friends meanwhile 8 (31\%) had mass media as a source of information and $4(16 \%)$ had information from their health professionals. M ost of the post caesarean mothers were practicing early initiation of breast feeding. Regarding the total practice score for the early initiation of breast feeding it was $6.38 \pm$ 0.696 and it ranged from 5 to 7 with a median 6.

Conclusion: The study has revealed that, most of the post caesarean mothers were practicing the early initiation breast feeding practices.

\section{Introduction}

Early skin to skin contact and opportunity to suckle have been identified as indicators in reducing the chances of breast engorgement. The severity of engorgement commonly occurs between $3^{\text {rd }}$ and $5^{\text {th }}$ day. More than twothirds of women will experience tenderness on $5^{\text {th }}$ day but some as late as $9^{\text {th }}$ or $10^{\text {th }}$ day $^{1}$. Exclusive breast feeding in the first two days is coupled with less engorgement 
(Brooten DA, 1989)2. Global rate of exclusive breastfeeding according to World Health Organization (WHO, 2013) is $37 \%$. Indian statistics suggests $96 \%$ of the children are breastfed, of that only $29 \%$ of the urban population and $21 \%$ of the rural population are breastfed within an hour of birth (lyengar K, 2012).

It has been identified cabbage leaves contains a chemical sinigrin called as allylisothiocyanate that is absorbed through skin, which reduces edema and increases milk flow. Cabbage has both antibiotic and anti-irritant properties. It improves the blood flow in and out of the area, allowing the body to reabsorb the fluid trapped in the breasts $^{3}$. The multiple therapeutic effect of cabbage leaf treatment, on women with breast engorgement did reduce pain, the hardness of the engorged breasts and increased the duration of breast feeding than any other nursing interventions.

Traditionally, the treatment for breast engorgement should be based on maintaining breastfeeding and systematic manual milking of the breast to balance milk supply and infant demand ${ }^{4}$. There is lack of knowledge among the nursing women regarding the care they could take to avoid or treat engorged breasts, considering that approximately $57 \%$ do not know what can be done to relieve engorgement symptoms, $23.7 \%$ know hot compresses or massages, $11.7 \%$ refer to milking, $6.4 \%$ breastfeed, $0.8 \%$ use medications, and $0.4 \%$ suspend breastfeeding when there is breast engorgement. Frequent breastfeeding is emphasized, whenever the baby feels hungry, besides advising mothers regarding the correct latching and sucking (Biancuzzo M, 1999).

Nursing research invites the nurses to explore all possible nursing interventions to give complete assistance to the post natal mothers who are suffering from breast engorgement with easily available materials. The investigator has done a systematic review about various modalities to treat breast engorgement and developed an evidence based practice guideline to deal with breast engorgement among post caesarean mothers.

\section{Materials and Methods}

In this study, one group pre test post test design was chosen. The study was conducted at KMC Hospital Attawara, Mangalore. The population in this study comprised of primi post caesarean mothers and staff nurses who are available at the period of data collection at KMC Hospital, Attawara, Mangalore. The calculated sample size for post caesarean mothers is 50 ad staff nurses is 20. In the present study, the investigator used non probability purposive sampling technique. The Institutional Research Committee of Manipal College of Nursing had examined and evaluated the research proposal. The study was accepted and approved by the Institutional Ethics Committee of Kasturba Hospital, Manipal. The investigator obtained administrative permission from Dean, Manipal College of Nursing, Manipal. Permission to conduct the main study was obtained from the Medical Superintendent and the Nursing Superintendent of KM C Hospital, Attawar. Written informed consent was obtained from every participant. Anonymity and confidentiality of the participants are safeguarded by the investigator in the study.

The following tools were developed by the investigator:

Tool: 1 Baseline characteristics - post caesarean mothers and staff nurses.

Tool:2 Structured knowledge questionnaire on prevention and treatment of breast engorgement.

Tool: 3 Observational checklist to identify early initiation of breast feeding.

Tool:4 Modified six point engorgement scale to assess the severity of breast engorgement.

\section{Results}

\section{Demographic characteristics- Post caesarean mothers and Staff nurses}

With regard to the sample characteristics, majority of the subjects 24 (48\%) were in the age group of $22-25$ years. It is observed that $22,(44 \%)$ of the subjects were having a qualification of PUC. The results of the study revealed that $23,(46 \%)$ of the subjects were un-employed. The data 
Original Article

regarding type of family depicted that $38,(76 \%)$ of the mothers belonged to joint family and $12,(24 \%)$ of them belonged to nuclear family. Out of the total subjects, 42 $(84 \%)$ were urban residents where as $8,(16 \%)$ of them residing in rural areas. Out of the 50 mothers, $26(52 \%)$ of the mothers had previous information regarding breast engorgement.

$M$ ajority of the staff nurses 11 (55\%) were in the age group of 26 - 29 years. It is observed that $14(70 \%)$ of the subjects were GNM Nurses and $6(30 \%)$ of the staff nurses were graduates. M ost of the subjects $12(60 \%)$ had $3-5$ years of experience and $5(25 \%)$ subjects had $0-2$ years of experience.

\section{Identification of early initiation of breast feeding by post caesarean mothers}

Most of the post caesarean mothers were practicing early initiation of breast feeding. Regarding the total practice score for the early initiation of breast feeding it was $6.38 \pm$ 0.696 and it ranged from 5 to 7 with a median 6.50.

Classification of staff nurses based on the pre test knowledge score $n=20$

\begin{tabular}{|l|l|c|c|c|c|}
\hline \multirow{2}{*}{$\begin{array}{l}\text { Knowledge } \\
\text { Level }\end{array}$} & Category & \multicolumn{2}{|c|}{ Respondents } & Mean & SD \\
\cline { 3 - 5 } & & Frequency (f) & Percent (\%) & & \\
\hline Good & $13-16$ score & 15 & 75 & 13.95 & 0.4987 \\
\hline Average & 7-12 Score & 05 & 25 & & \\
\hline Poor & $0-6$ Score & 00 & 00 & & \\
\hline Total & 20 & 100.0 & & & \\
\hline
\end{tabular}

The table shows that 15 (75\%) of the staff nurses had good knowledge and $5(25 \%)$ of the staff nurses had average knowledge with mean of 13.95 and SD 0.4987 regarding prevention and treatment of breast engorgement among post caesarean mothers.

Severity of breast engorgement using modified breast engorgement scale.

Description of severity of breast engorgement in terms of frequency and percentage

\begin{tabular}{|l|c|c|c|c|}
\hline \multirow{2}{*}{} & \multicolumn{4}{|c|}{ Severity of breast engorgement } \\
\cline { 2 - 5 } & \multicolumn{2}{|c|}{$3^{\text {rd }}$ day $(\mathrm{n}=50)$} & \multicolumn{2}{|c|}{$5^{\text {th }}$ day $(\mathrm{n}=49)$} \\
\cline { 2 - 5 } & Frequency & Percentage & Frequency & Percentage \\
\cline { 2 - 5 } & $(\mathrm{f})$ & $(\%)$ & $(\mathrm{f})$ & $(\%)$ \\
\hline Nil & 1 & 2 & & \\
\hline Mild (1-4) & 13 & 26 & 29 & 88 \\
\hline M oderate (5-8) & 24 & 48 & 4 & 12 \\
\hline Severe (9-12) & 12 & 24 & & \\
\hline
\end{tabular}

Table shows that severity of breast engorgement on the $3^{\text {rd }}$ day and $5^{\text {th }}$ day. There were $13(26 \%)$ post caesarean mothers who had mild breast engorgement, $24(48 \%)$ of the post caesarean mothers had moderate breast engorgement and 12 (24\%) of the post caesarean mothers had severe breast engorgement on the $3^{\text {rd }}$ day. There was a post caesarean mother without breast engorgement on $3^{\text {rd }}$ day. On the fifth day out of 49 post caesarean mothers, 33 post caesarean mothers were identified with breast engorgement. Of these 29 (88\%) were in mild category and $4(12 \%)$ were in moderate breast engorgement group. There was no cases of either severe or no breast engorgement on the $5^{\text {th }}$ day.

Difference between severity of breast engorgement on $3^{\text {rd }}$ and $5^{\text {th }}$ day by using Wilcox son signed rank test.

\begin{tabular}{|l|c|c|c|c|}
\hline & Median & IQR & Z value & p value \\
\hline $\begin{array}{l}\mathbf{3}^{\text {rd }} \text { day } \\
(\mathbf{n}=\mathbf{5 0}) \\
<0.001\end{array}$ & 2.00 & $1-2.25$ & 6.418 & \\
$\begin{array}{l}\mathbf{5}^{\text {th }} \text { day } \\
(\mathbf{n}=\mathbf{4 9})\end{array}$ & 1.00 & $0.0-1$ & & $<0.001$ \\
\hline
\end{tabular}

Table 8 shows that, severity of breast engorgement median on the $3^{\text {rd }}$ day was 2.00 with an inter quartile range of 1 2.25.The median on the $5^{\text {th }}$ day was 1.00 with an inter quartile range of $0.0-1$. Wilcox son signed rank test was employed as a test of significance on computation. The obtained $Z$ value was 6.418 with $p$ value of 0.001 . As the $p$ value is less than 0.05 evidence based practice guideline was effective at $5 \%$ level of significance. Hence, the null hypothesis was rejected and research hypothesis was accepted.

\section{Conclusion}

The study has revealed that, most of the post caesarean mothers were practicing the early initiation breast feeding practices. Regarding the severity of breast engorgement on the $3^{\text {rd }}$ day $13(26 \%)$ of the mothers had mild engorgement, $24(48 \%)$ of the mothers had moderate engorgement and $12(24 \%)$ of the mothers had severe engorgement. There was a woman without an engorgement on $3^{\text {rd }}$ day. On the fifth day 33 women were identified with breast engorgement. Of these 29 (88\%) were in mild category and 
$4(12 \%)$ were in moderate engorgement group. There were no cases of either severe or no engorgement on the $5^{\text {th }}$ day. The EBP training programme on prevention and treatment

\section{References}

1. Auerbach, R. (1998). Breast feeding and Human lactation. Sudbry: Joones and Bartlett.

2. Brooten, B. (1989). Acomparison of foue treatments to prevent and control breast pain and engorgement in non nursing mothers. JObstet Gynecol Neonatal Nurs.

3. BiancuzzoM . (1999). Breast feeding the Newborn :clinical strategies for Nurses. St.Louis: M osby.

4. Brian, v. L. (2012). Ultrasound as atreatment of mammary blocked duct among post partum lactating women.J Chioropr M ed, 170-178.

5. Chi JY, G. M. (2010). Effects of Guasha therapy on breast engorgement: Arandomized controlled trial. J Nurs Res, 1-10.

6. Denise F. Polit, Cheryl Tatano Beck. (2012). Nursing Research:Generating and assesing evidence for nursing practice. New Delhi: Wolters Kluwer Health / Lippincott Williams \& Wilkins.

7. Duong, B. (2004). Breast feeding initiation and exclusive breast feeding in rural vietanam. Public health Nutr, 795-9.

8. Dowswell, M. L. (2010). Treatments for breast engorgement during lactation. Cchrane databae Systeatic review . of breast engorgement need to be re-enforced from time to time to bring out reduction in the incidence of breast engorgement among post natal mothers. 